\title{
CAMILLERI, SYLVAIN. HEIDEGGER ET LES GRANDES LIGNES D'UNE PHÉNOMÉNOLOGIE HERMENNEUTIQUE DU CHRISTIANISME PRIMITIF. 845 PP. DORDRECHT, 2018: SPRINGER
}

Prof. Dr. Jimmy Hernández Marcelo

Universidad de Salamanca, España Laboratorio de Ontología, Universidad de Turín, Italia

Sylvain Camilleri, ${ }^{1}$ profesor de la Universidad de Lovaina, gran especialista en el pensamiento de Martin Heidegger publica en 2018 una versión revisada del texto de su tesis doctoral con el título Heidegger y las grandes líneas de una fenomenología hermenéutica del cristianismo primitivo. Esta importante contribución a la filosofía del joven Heidegger y, en concreto, a su filosofía de la religión pone de manifiesto una perspectiva no bien atendida en la evolución de la filosofía de este importante filósofo alemán. Según nos confiesa el propio autor, su escrito gira en torno al volumen 60 de las obras completas de Heidegger "Einleitung in die Phänomenologie der Religion: Frühe Freiburger Vorlesung Wintersemester 1920-1921" (1995).

Desde el principio, en una extensa Introducción (pp. XIX-LXXXII), el lector será capaz de reconocer la seriedad con la que el autor se consagra a la reconstrucción e interpretación del proyecto inicial que el joven Heidegger tenía de una fenomenología de la religión, cuyo eje central se encontraría en el giro hermenéutico vinculado a las Sagradas Escrituras. En esta Introducción se lleva a cabo un cuidadoso estudio comparativo de las distintitas versiones del manuscrito que dan lugar a la Introducción a la fenomenología de la religión del volumen 60, del que hemos hecho mención más arriba. A partir de ahora, todo estudioso de la obra de Heidegger no puede dejar de tomar en consideración esta "reconstrucción" del texto, si se busca comprenderlo íntegramente en su sentido y alcance.

El libro está compuesto de dos partes: La primera, "Problemas de método" (pp. 1-269) y La segunda, "Ejercicios de lectura" (pp. 271-802). En la primera parte el profesor Camilleri busca comprender la intención de Heidegger al explicar la

\footnotetext{
${ }^{1}$ Entre sus principales escritos encontramos la monografía Phénoménologie de la religion et herméneutique théologique dans la pensée du jeune Heidegger. Commentaire analytique des Fondements philosophiques de la mystique médiévale (1916-1919). Dordrecht, Springer, 2008. Además de un número considerable de artículos entre los que cabe mencionar, "Le jeune Heidegger à l'école du christianisme", en Études théologiques et religieuses, 2016/2 (Tome 91), p. 221-237, "Bereshit: éléments pour une phénoménologie génétique biblique", en Recherches de Science Religieuse, 2007/3 (Tome 95), p. 393-416. En castellano ha publicado "Heidegger y Kierkegaard: En el comienzo", en Disputatio [Diciembre 2017], Volumen 6, Número 7, pp. 81-101.
} 
particularidad de la experiencia religiosa y la capacidad de la fenomenología de poder penetrar la esfera de lo religioso y, al mismo tiempo, respetar la singularidad de la experiencia religiosa. De este modo, el libro expone la concepción de la filosofía y su diferencia frente a la Weltanschuung, la propuesta de un estudio como introducción, los debates sobre la experiencia fáctica (Husserl, Dilthey, Natorp) y las innovaciones terminológicas del proyecto heideggeriano. A continuación, se expone el pensamiento de Ernst Troeltsch como soporte filosófico de la filosofía de la religión de Heidegger. En un tercer momento se aborda el tema de la singularidad de lo histórico como fenómeno seminal, las diferentes concepciones y debates en el mundo de la filosofía sobre la vida y lo histórico y, finalmente, la teorización de la experiencia fáctica. El cuarto y último apartado de la primera parte expone el itinerario hacia una forma de indicación formal.

La segunda parte del libro se concentra en los comentarios bíblicos hechos por Heidegger. A partir de estos comentarios a las Cartas paulinas (Gálatas, 1 y 2 Tesalonicenses) se obtienen explicaciones que van de lo proto-fenomenológico a lo fenomenológico en sentido estricto. Asimismo, la religión se presenta estando entre la fenomenología y la historia. Por último, esta parte se concluye con un estudio fenomenológico de la experiencia proto-cristiana de la vida a partir de esta especie de hermenéutica fenomenológica del texto bíblico.

La Conclusión (803-814) es una invitación a volver al método fenomenológico-hermenéutico del joven Heidegger, a fin de reconstituir el valor de una auténtica fenomenología de la religión. Por último, la Bibliografía (pp. 815-845) presentada por el autor es una excelente herramienta de investigación que resultará de mucha utilidad para todos los investigadores que deseen profundizar en la filosofía de la religión de Heidegger. Aquí no solo se enumeran obras de orden filosófico, sino también teológico. Además, el investigador encontrará las referencias a los estudios más recientes sobre el tema, así como también los ya consagrados como clásicos. 